\title{
INVESTIGATION OF CONTACT STRESSES IN THE ECCENTRIC ROLLING TRANSMISSION
}

\author{
Pabiszczak, S. \& Staniek, R. \\ Poznan University of Technology, Faculty of Mechanical Engineering and Management, \\ Pl. Marii Skłodowskiej-Curie 5, 60-965 Poznań, Poland \\ E-Mail: stanislaw.pabiszczak@ put.poznan.pl
}

\begin{abstract}
The aim of the article is to present an analytical and a simulation model for the determination of the contact stresses in the eccentric rolling transmission. The stresses within the contact area of the eccentric unit and the cam wheel were analysed in accordance with the Hertz theory. 2D and 3D models for the finite element method (FEM) analysis were developed and the simulation results were compared with those of theoretical analyses. The influence of the eccentricity value and the dimensions of the bearing in the eccentric unit on the maximum and average values of contact stresses were investigated. The conducted research showed that, due to the contact stresses, it is advantageous to choose the bearing with the largest possible width and smallest outside diameter, and to apply low eccentricity values.

(Received in August 2019, accepted in December 2019. This paper was with the authors 1 month for 2 revisions.)
\end{abstract}

Key Words: Eccentric Rolling Transmission, Contact Stress, FEM Simulation

\section{INTRODUCTION}

Mechanical transmissions are widely used in machine and vehicle drives, and the constantly increasing requirements of drive units encourage searching for new design solutions. Recent years have brought a growing interest in the drives with rolling elements that mediate power transmission. The use of rolling elements contributes to the elimination of sliding friction between the cooperating surfaces of the transmission components, which affords improvement in the operational properties of the drives. Examples of rolling transmissions used in practice are, among others, cycloidal drives, ball worm gears, or continuously variable transmissions (CVTs).

The subject of this article is a new kind of mechanical transmission - the eccentric rolling transmission (ERT) [1]. In previous studies, its geometry and kinematics [2] as well as the influence of technological inaccuracies on contact stress values have been analysed and simulated [3]. The aim of this article is to present the theoretical basis as well as the analytical and simulation models for the calculation of contact stresses on the surfaces of active components of the ERT. The executed tests and analyses allow determining the strength and durability of the new mechanical transmission.

Contact stresses are the subject of numerous scientific publications, and the analyses presented therein are based primarily on the Hertz theory [4]. For example, in [5], the results of theoretical calculations for the contact of two cylindrical surfaces were compared with the simulation results of the $2 \mathrm{D}$ model, while in [6], the results obtained for the $2 \mathrm{D}$ and $3 \mathrm{D}$ models were shown. When analysing the contact stresses in cam mechanisms, it is necessary to consider a variable radius of the contacting surfaces curvature in the theoretical model, as shown in [7], while in [8], a detailed stress analysis was performed within the contact area of cam mechanism elements. Impact of microgeometry on contact stress and coefficient of friction was investigated in [9, 10]. Most studies on contact stresses in mechanical transmissions [11] relate to spur and helical gears, which are among the most common in technology. In several available publications, results of the finite elements method (FEM) 
simulation tests of the distribution of contact stresses in such transmissions were compared with the outcomes of theoretical analyses $[12,13]$ or calculations in accordance with the applicable standards [14, 15]. Numerical methods have also been used to evaluate the proposed methods of tooth profile modification [16-18]. Research efforts have been also focused on the improvement of simulation models of gears, e.g., to reduce computational costs [19]. FEM analyses are extremely useful in the study of load distribution, e.g.: in bearings [20, 21] and in gears characterized by complex geometry, such as cycloidal drives $[22,23]$. In the case of such transmissions, it is also necessary to take into account the research, which presents the results of simulations of stress and deformation in structural elements with geometrical discontinuities [24] and show the influence of residual stresses on wear in the case of line rolling contact [25].

The structure of this article is as follows: First, the construction and the principles of operation of the eccentric rolling transmission are presented and the main parameters influencing the functional properties of the ERT are indicated. Next, the analytical model used to calculate the contact stresses within the contact area of the main transmission components is addressed. Subsequently, the FEM 2D and 3D models of the transmission with selected constructional parameters are presented and the results of theoretical analyses and simulation are discussed. The presented models afforded the basis for comprehensive analysis of the impact of individual construction parameters, such as the eccentricity value and the dimensions of the bearing, on the obtained values of contact stresses.

\section{CONCEPT OF THE ECCENTRIC ROLLING TRANSMISSION}

The ERT concept is presented in Fig. 1. It is a transmission with parallel, non-overlapping shaft axes. Eccentric units, consisting of an eccentric bush with a rolling bearing, are mounted on an input shaft. The rotation of the input shaft causes the outside surfaces of the rolling bearings to roll over the active surfaces of cam wheels mounted coaxially on an output shaft, causing it to rotate. It should be emphasized that the shafts do not move, either in relation to the transmission housing or each other.
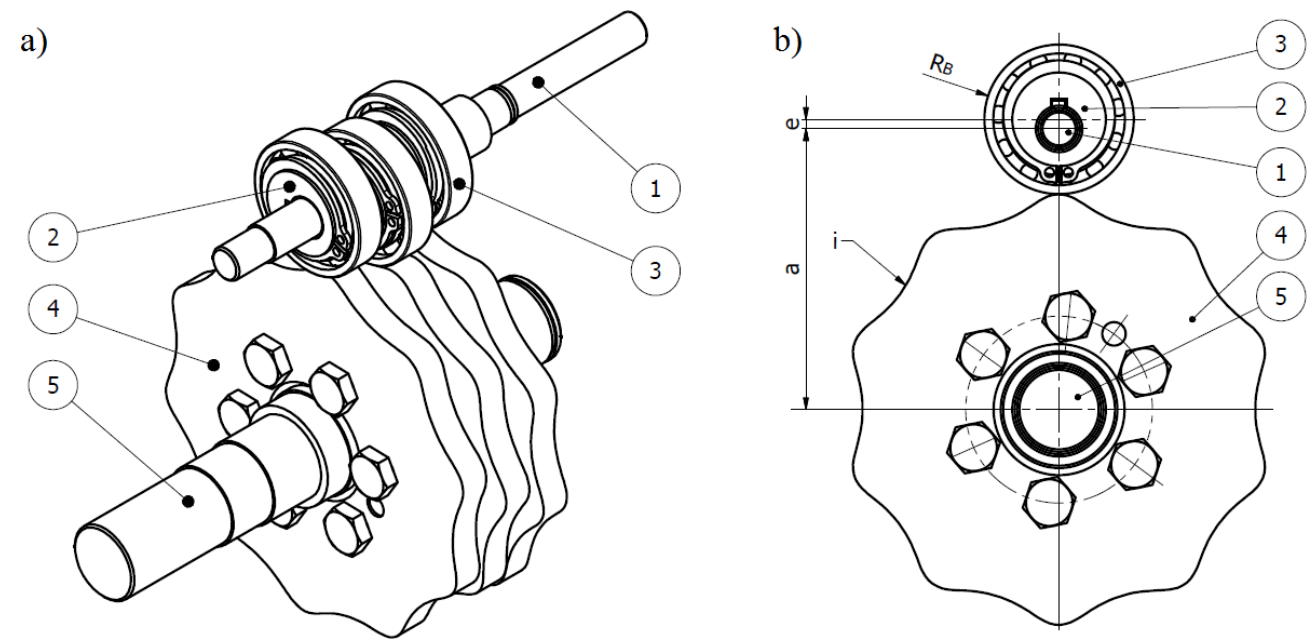

Figure 1: Concept of the eccentric rolling transmission (ERT): a) 3D view; b) front view of a single eccentric unit - cam wheel pair;

1 - input shaft, 2 - eccentric bush, 3 - rolling bearing, 4 - cam wheel, 5 - output shaft.

Each eccentric unit corresponds to one cam wheel and the individual pairs: eccentric unit - cam wheel are evenly distributed in relation to the shaft axis. To ensure the continuity of the drive transmission, at least three such pairs are necessary (this problem will be discussed in detail in the further part of the article). 
Continuity of contact between cooperating surfaces of the transmission elements is ensured by a special profile of the cam wheels - an envelope of motion of the eccentric unit and the cam wheel for the assumed gear ratio. The shape of the cam profile depends on the gear ratio $i$, the assumed eccentricity value $e$, the distance between shaft axes $a$, and the outside radius of the eccentric unit bearing $R_{\mathrm{B}}$.

The transmission ratio equals the ratio of the angular velocity of its shafts, while the gear ratio corresponds to the number of vertices in the profile of the cam wheel. Due to the rolling friction between the cooperating surfaces, the transmission is not self-locking, which means that the drive can be applied to the input shaft (with the ERT acting as a reducer) or to the output shaft (the ERT is a multiplier).

\section{ANALITICAL STUDY OF CONTACT STRESSES}

The permissible load value for the ERT depends on the strength and stiffness of the transmission shafts, the transmission housing, or the rolling bearings used. Particular attention should be paid to the values of contact stress within the area where the outer surfaces of the bearings in the eccentric units are in contact with the active surfaces of the cam wheels. In order to develop an analytical model for the calculation of contact stresses in the ERT, one eccentric unit - cam wheel pair was first considered. The obtained equations allow for the generation of a model of the entire transmission unit, consisting of three such pairs. The model presented in this article does not take into account the phenomena occurring in the bearings themselves (on the contact surface of the bearing raceway and the rolling elements), treating them as rigid bodies.

\subsection{One eccentric unit - cam wheel pair}

To determine the stress distribution on the active surface of the cam wheel, the model shown in Fig. 2 was prepared. Point $B$ corresponds to the axis of the input shaft, point $O$ is the centre of the output shaft, and point $C$ is the bearing centre in the eccentric unit. The position of the point $B$ relative to the global $O X Y$ coordinate system is described by the angle $\varphi$. Point $A$ defines the contact point of the outer surface of the rolling bearing and the active surface of the cam wheel. Vector $\overrightarrow{\mathrm{OA}}$, whose inclination relative to the $O X$ axis describes the angle $\gamma$, corresponds to the contact radius vector $\overrightarrow{R_{\mathrm{T}}}$.

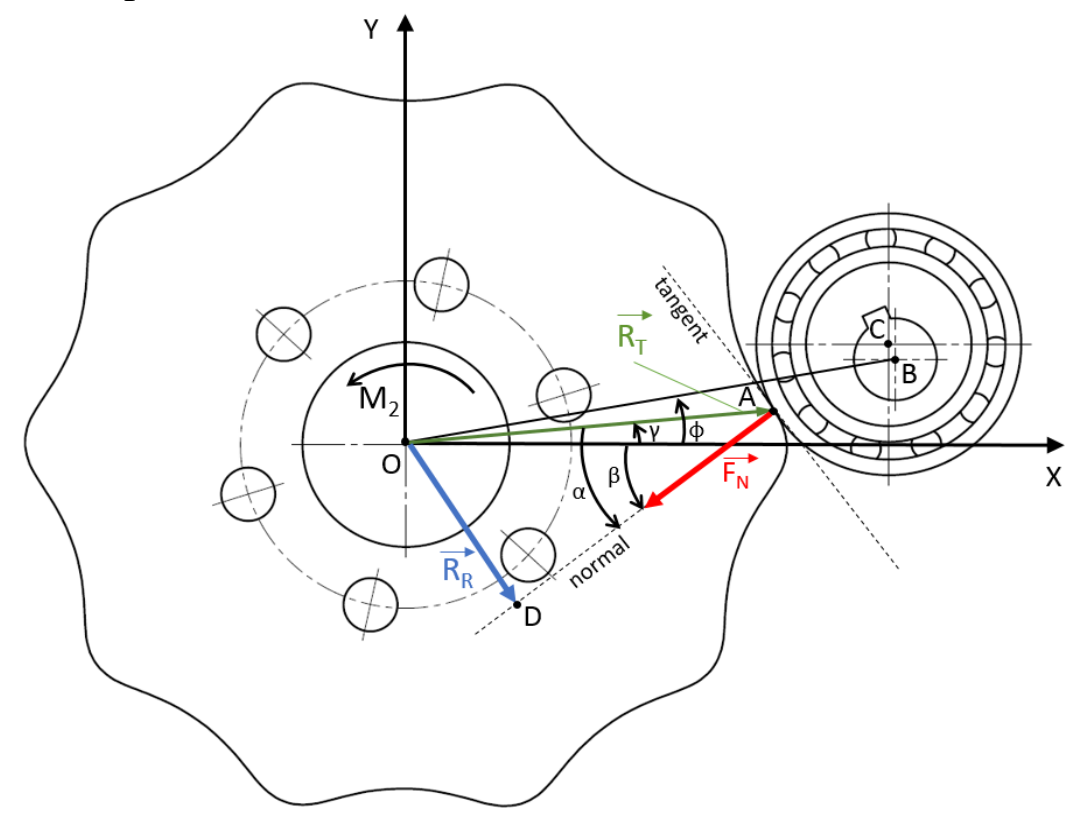

Figure 2: Model for determination of contact stress distribution. 
Applying the torque $M_{2}$ to the output shaft results in the reaction force $\overrightarrow{F_{\mathrm{N}}}$ acting in the direction normal to the curve describing the profile of the cam wheel. The equation of static equilibrium for the presented system is:

$$
\mathrm{M}_{2}=F_{\mathrm{N}}(\varphi) \cdot R_{\mathrm{R}}(\varphi)
$$

where $R_{\mathrm{R}}(\varphi)$ is the length of the rolling radius vector $\overrightarrow{R_{\mathrm{R}}}$ perpendicular to the direction of $\overrightarrow{F_{\mathrm{N}}}$.

To determine the normal force distribution, the coordinates of point $A\left(x_{\mathrm{A}}(\varphi), y_{\mathrm{A}}(\varphi)\right)$ in the $O X Y$ coordinate system should first be established [15]:

$$
\begin{aligned}
& x_{\mathrm{A}}(\varphi)=x_{\mathrm{C}}(\varphi)-\frac{\mathrm{R}_{\mathrm{B}} y_{\mathrm{C}}^{\prime}}{\sqrt{x_{\mathrm{C}}^{\prime 2}+y_{\mathrm{C}}^{\prime 2}}} \\
& y_{\mathrm{A}}(\varphi)=y_{\mathrm{C}}(\varphi)+\frac{\mathrm{R}_{\mathrm{B}} x_{\mathrm{C}}^{\prime}}{\sqrt{x_{\mathrm{C}}{ }^{\prime 2}+y_{\mathrm{C}}^{\prime 2}}}
\end{aligned}
$$

where $R_{\mathrm{B}}$ is an outside radius of the bearing in the eccentric unit, and $x_{\mathrm{c}}(\varphi), y_{\mathrm{c}}(\varphi)$ are the coordinates of point $C$ calculated by equations:

$$
\begin{aligned}
& x_{C}(\varphi)=a \cdot \cos (\varphi)+e \cdot \cos (\varphi \cdot(i+1)) \\
& y_{C}(\varphi)=a \cdot \sin (\varphi)+e \cdot \sin (\varphi \cdot(i+1))
\end{aligned}
$$

Knowing the coordinates of point $A$, the value of the contact radius $R_{\mathrm{T}}$ can be determined:

$$
\left|R_{\mathrm{T}}(\varphi)\right|=\sqrt{x_{\mathrm{A}}(\varphi)^{2}+y_{\mathrm{A}}(\varphi)^{2}}
$$

Analysis of the Eq. (1) shows that in order to determine the value of the normal force at the contact point of the bearing and the cam wheel, it is necessary to calculate the value of the rolling radius $R_{\mathrm{R}}(\varphi)$. The following relationship results from the right-angled triangle $O A D$ :

$$
R_{\mathrm{R}}(\varphi)=\left|R_{\mathrm{T}}(\varphi) \cdot \sin (\alpha(\varphi))\right|
$$

where $\alpha(\varphi)$ is the angle between vector $\overrightarrow{R_{\mathrm{T}}}$ and the normal to the curve at point $A$. To determine the value of angle $\alpha$, it is necessary to define the angle $\gamma(\varphi)$ between the vector $\overrightarrow{R_{\mathrm{T}}}$ and the $O X$ axis and the angle $\beta(\varphi)$ between the $O X$ axis and the normal to the curve at point A.

The angle $\gamma(\varphi)$ can be calculated from the following equation:

$$
\gamma(\varphi)=\arctan \left(\frac{y_{\mathrm{A}}(\varphi)}{x_{\mathrm{A}}(\varphi)}\right)
$$

The value of angle $\beta(\varphi)$ corresponds to the slope of the normal to the profile of the cam wheel at point $A$ :

$$
\beta(\varphi)=\arctan \left(\frac{-x_{\mathrm{A}}^{\prime}(\varphi)}{y_{\mathrm{A}}^{\prime}(\varphi)}\right)
$$

The angle $\alpha(\varphi)$ is then calculated based on the equation:

$$
\alpha(\varphi)=|\beta(\varphi)|+|\gamma(\varphi)|
$$

In order to determine the stress distribution on the contact surface of the bearing and the cam wheel, a model based on the Hertz's theory for the contact of a constant radius cylinder with a surface with a variable curvature radius was adopted. The contact stresses between the outer surface of the bearing and the active surface of the cam wheel, assuming both elements are made of the same material, are calculated as follows: 


$$
\sigma_{H}(\varphi)=\sqrt{\frac{\mathrm{M}_{2} \cdot \mathrm{E}}{2 \cdot \pi \cdot\left(1-v^{2}\right) \cdot \mathrm{b} \cdot R_{\mathrm{R}}(\varphi) \cdot \frac{1}{\frac{1}{\mathrm{R}_{\mathrm{B}}}+\frac{1}{R_{\mathrm{K}}(\varphi)}}}}
$$

where $E$ is the modulus of elasticity, $v$ is the Poisson's ratio, $b$ is the bearing (or cam wheel) width, and $R_{\mathrm{K}}(\varphi)$ is the radius of curvature of the cam profile at point $A$.

The value of the latter can be calculated from the following equation [17]:

$$
R_{\mathrm{K}}(\varphi)=\frac{\left(x^{\prime}{ }_{A}(\varphi)^{2}+y^{\prime}{ }_{A}(\varphi)^{2}\right)^{\frac{3}{2}}}{\left|y^{\prime \prime}{ }_{A}(\varphi) \cdot x^{\prime}(\varphi)-x^{\prime \prime}{ }_{A}(\varphi) \cdot y_{A}^{\prime}(\varphi)\right|}
$$

\subsection{Three eccentric unit - cam wheel pairs}

As mentioned earlier, the continuity of the ERT drive transmission depends on the number of eccentric unit - cam wheel pairs. This problem is shown in Fig. 3.

a)
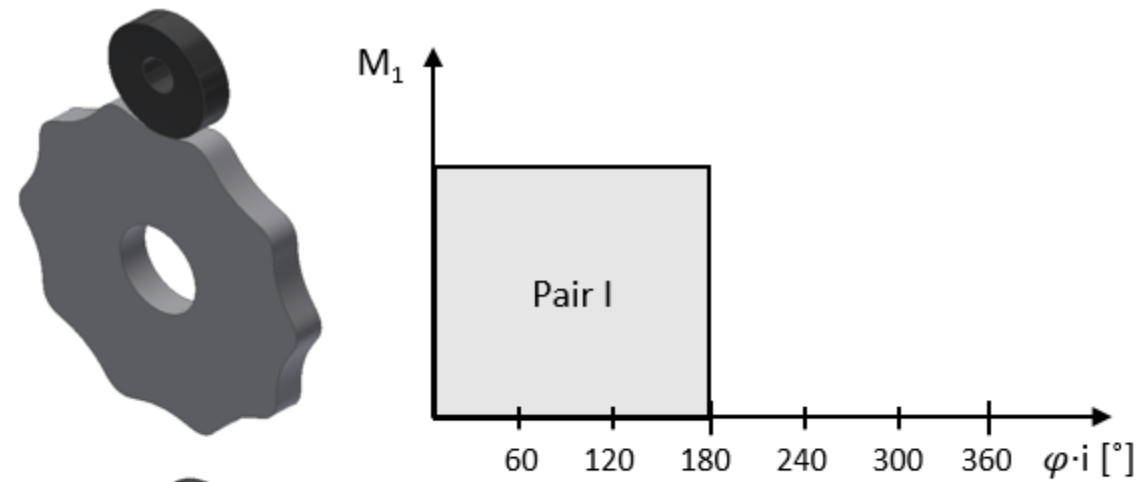

b)
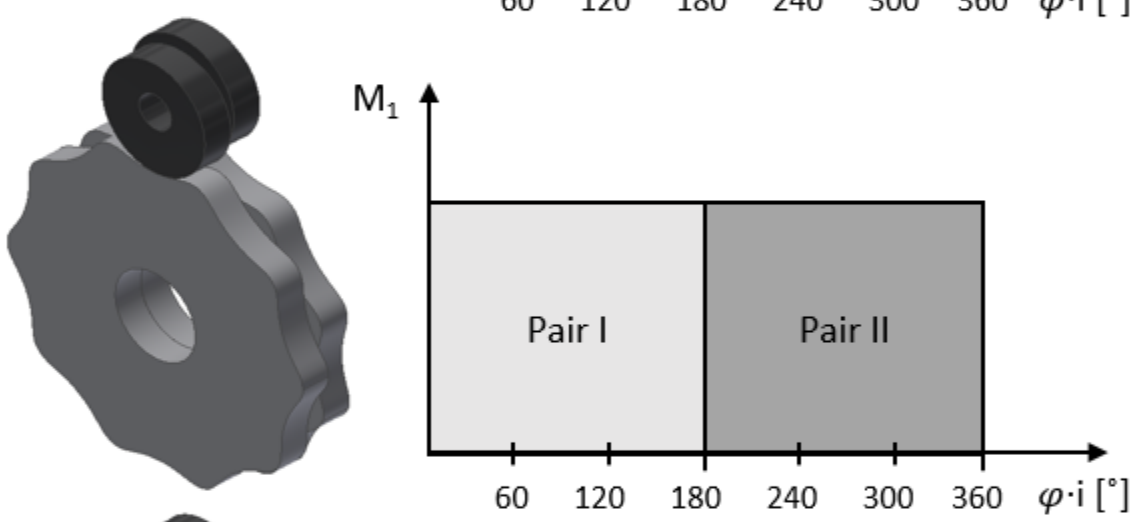

c)
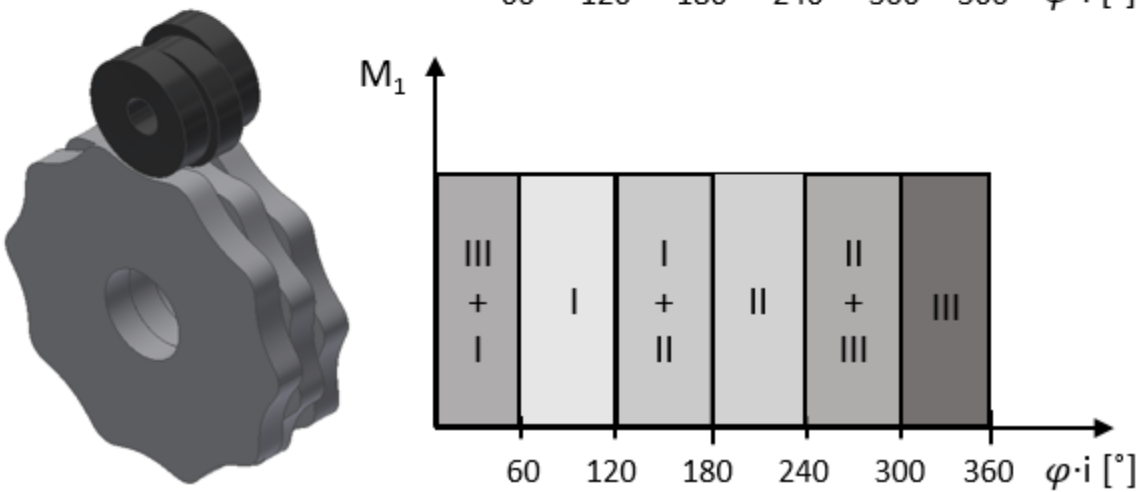

Figure 3: The problem of drive transmission continuity in the eccentric rolling transmission for:

a) one, b) two, c) three eccentric unit - cam wheel pairs;

$M_{1}$ - torque in the input shaft, $\varphi \cdot \mathrm{i}-$ angular position of the input shaft. 
If one pair was used (Fig. 3 a), the drive would be transmitted only within half the rotation of the input shaft. Subsequently, the contact between the bearing and the cam wheel would break causing the output shaft to rotate rapidly until it reached the position at which the surfaces of the active gear components came into contact again. If the transmission unit consisted of two eccentric unit - cam wheel pairs (Fig. $3 \mathrm{~b}$ ), the contact points of the active elements corresponding to the extremum of the function describing the profile of the cam wheels (position of the input shaft, $0^{\circ}, 180^{\circ}, 360^{\circ}$, etc.) would be loose. Only the use of three pairs (Fig. $3 \mathrm{c}$ ) guarantees the continuity of drive transmission and ensures torsional stiffness of the entire transmission unit.

Having taken the aforementioned considerations into account, a model was developed for the determination of contact stress distribution for three eccentric unit - cam wheel pairs. Assuming that the overall torque, that load the transmission unit, is distributed evenly to each cooperating pair, the drive is transmitted cyclically (every $60^{\circ}$ of the input shaft rotation) by one or two eccentric unit - cam wheel pairs. The equations describing the Hertz stresses within the contact area of the active transmission components (made of steel) as a function of the angular position of the input shaft $(\varphi \cdot \mathrm{i})$ are given in Table I.

Table I: Equations describing Hertz stresses in the ERT depending on the angular position of the input shaft $(\varphi \cdot \mathrm{i})$.

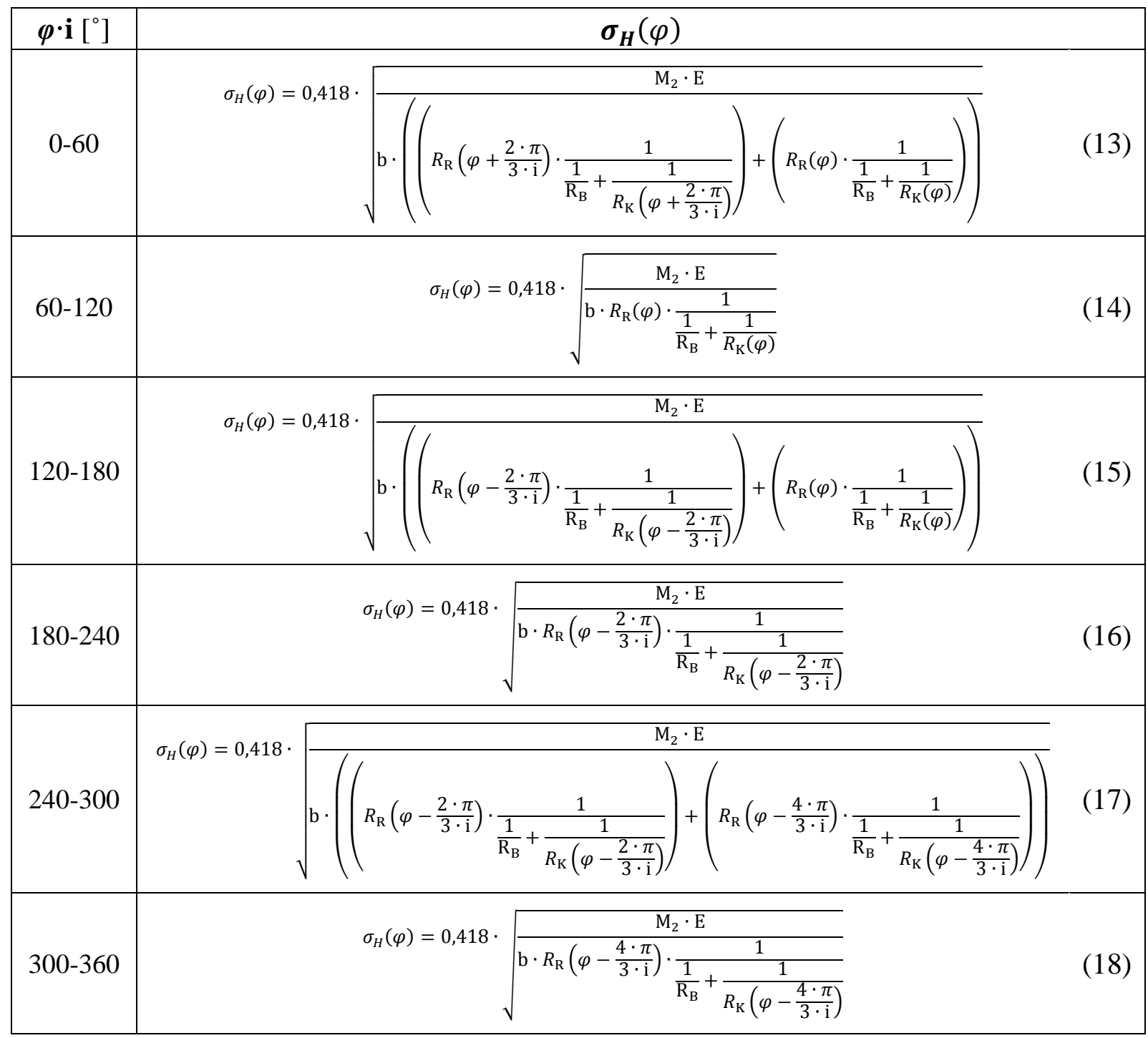




\section{SIMULATION STUDY OF CONTACT STRESSES}

\subsection{One eccentric unit - cam wheel pair}

In order to verify the analyses described in section 3.1, in the FEM software a twodimensional quasi-static model of a single eccentric unit - cam wheel pair was developed (Fig. 4 a) for the ERT parameters shown in Table II. The eccentric unit was assumed to be a homogeneous fixed solid, while the cam wheel model has one degree of freedom (rotation around the axis of the output shaft). Both the cam wheel and the eccentric assembly were made of steel. Torque $M_{2}$ was applied to the surface of the mounting hole of the cam wheel. A frictionless contact type between the cooperating surfaces was determined. An automatic quadrilateral meshing method (average element size of $1.45 \mathrm{~mm}$ ) was adopted and followed by local mesh refinement around the contact edges (element size of $0.025 \mathrm{~mm}$ ). An example of stress distribution within the contact area of the outside surface of the bearing and the active surface of the cam wheel is shown in Fig. 4 b.

Simulations were executed for the angular position of the input shaft in the $15^{\circ}-175^{\circ}$ range with a step of $5^{\circ}$. It was not possible to perform simulations for values between $0^{\circ}-15$ and $175^{\circ}-360^{\circ}$, as the application of torque to the cam wheel led to a break of contact between the cooperating surfaces, which resulted in multiple rotations of the cam wheel around the output shaft axis. The simulation results, as compared to those of analytical calculations, are shown in Fig. 5.

Table II: Parameters of the ERT model.

\begin{tabular}{|l|c|c|}
\hline \multicolumn{1}{|c|}{ Parameter } & Value & Unit \\
\hline Gear ratio $i$ & 10 & - \\
\hline Distance between shaft axes $a$ & 60 & $\mathrm{~mm}$ \\
\hline Bearing size (according to ISO 15) & 61804 & - \\
\hline Outside radius of bearing $R_{\mathrm{B}}$ & 16 & $\mathrm{~mm}$ \\
\hline Bearing width $b$ & 7 & $\mathrm{~mm}$ \\
\hline Torque (load) $M_{2}$ & 10 & $\mathrm{Nm}$ \\
\hline
\end{tabular}

a)

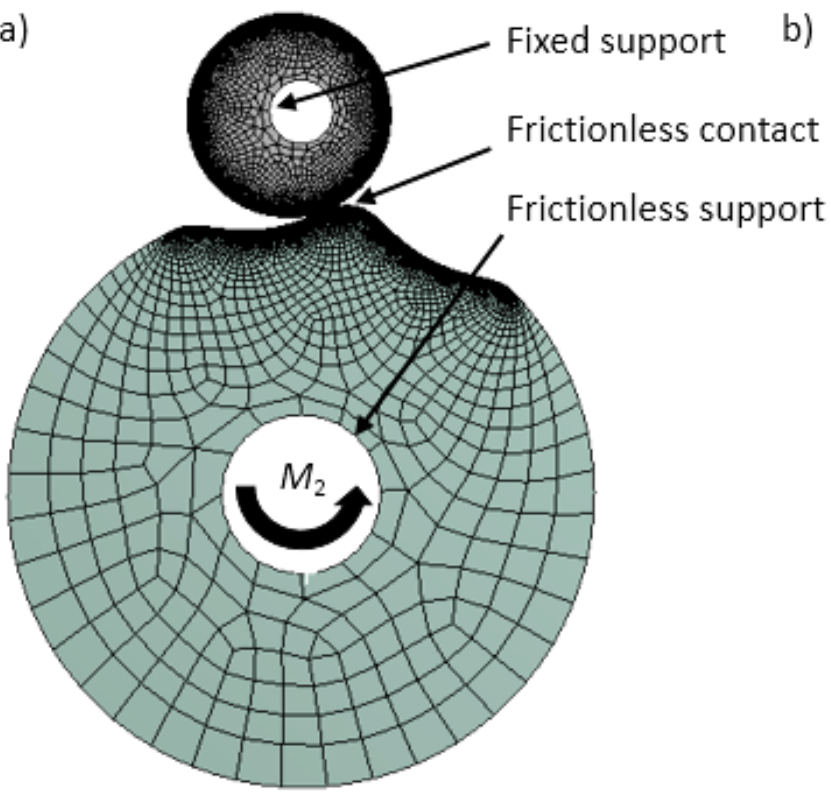

b)

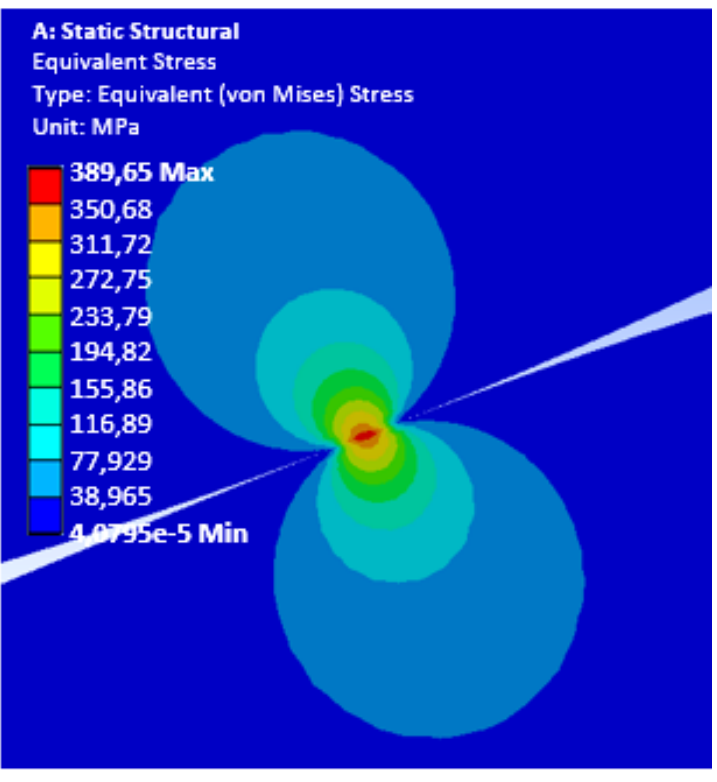

Figure 4: 2D simulation model of the ERT single eccentric unit - cam wheel pair:

a) adopted model with local mesh refinement, b) example of simulation result. 


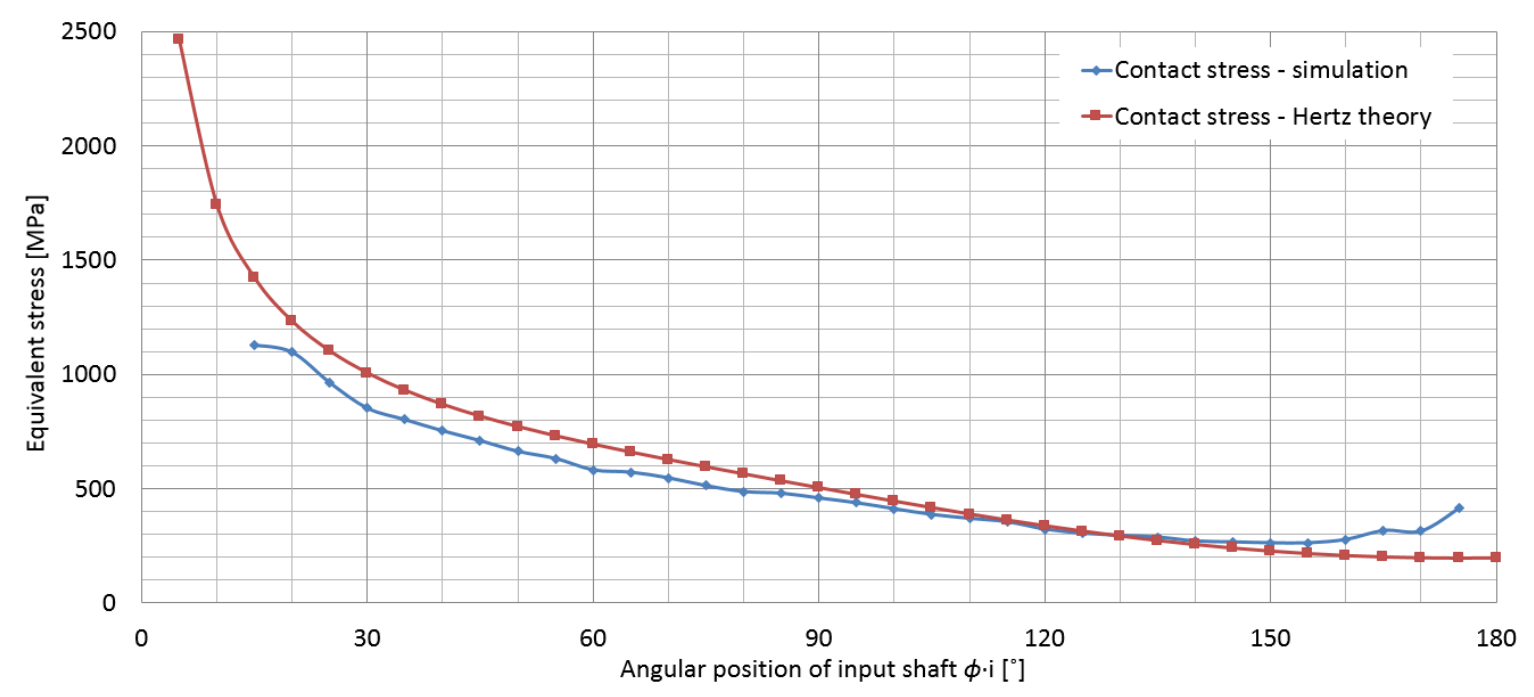

Figure 5: Comparison of contact stress values as a function of the angular position of the input shaft for the analytical and simulation models of one eccentric unit - cam wheel pair.

The graphs in Fig. 5 show a clear convergence between the results of theoretical analyses and the simulation outcomes. In the investigated transmission model, the maximal contact stresses occur near the vertex of the cam wheel (corresponding to the maximum of the function describing the profile of the cam wheel) and significantly exceed the allowable stress numbers $\sigma_{\mathrm{Hlim}}$, which equals approx. $500 \mathrm{MPa}$ in case of carbon steel (without or with poor heat treatment) $[26,27]$. Only in the range of the angular position of the input shaft of $90^{\circ}$ $180^{\circ}$, the values of stress in the contact area for a given load were within the acceptable limits.

\subsection{Three eccentric unit - cam wheel pairs}

Based on the model described in section 4.1, a 3D simulation model for the ERT with three eccentric unit - cam wheel pairs was developed. Similar to the 2D FEM analysis, the eccentric units were modelled as one fixed solid, one degree of freedom was provided to the cam wheels, and the torque $M_{2}$ was applied to the point of assembly of the cam wheels on the output shaft. A tetrahedral meshing method with local refinement within the contact area (element size of $0.2 \mathrm{~mm}$ ) was used and the frictionless contact type was determined. Fig. 6 shows the simulation model and an example of stress distribution upon the active surfaces of the cam wheels, while the comparative results of simulations and theoretical analyses are presented in Fig. 7.

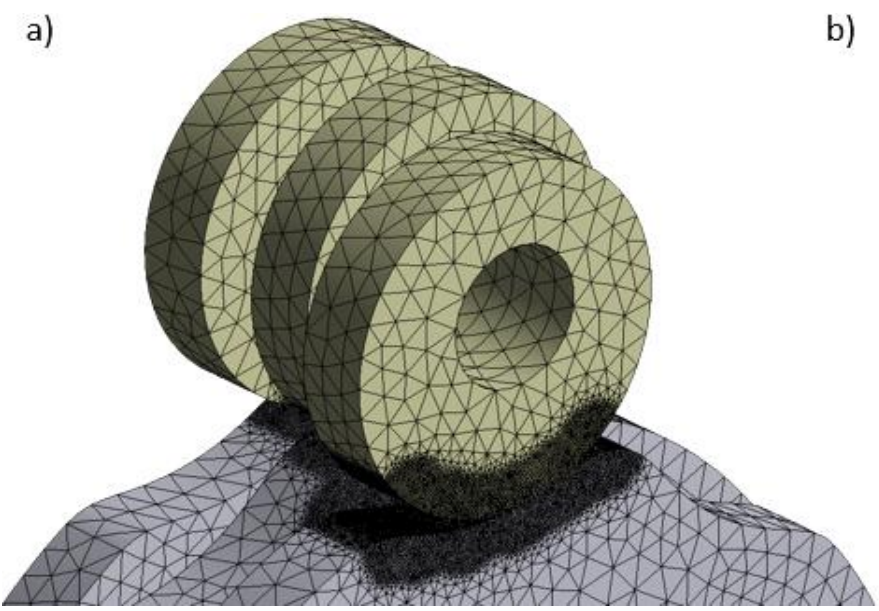

b)

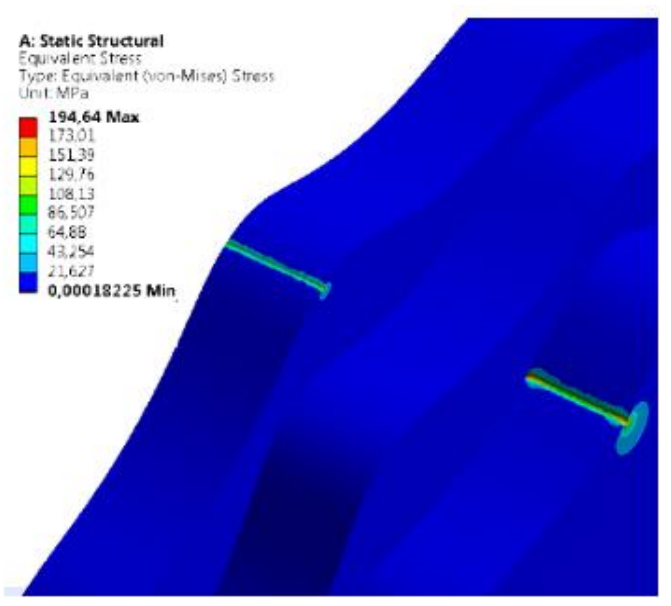

Figure 6: 3D ERT simulation model for three eccentric unit - cam wheel pairs:

a) local mesh refinement, b) example of simulation result. 


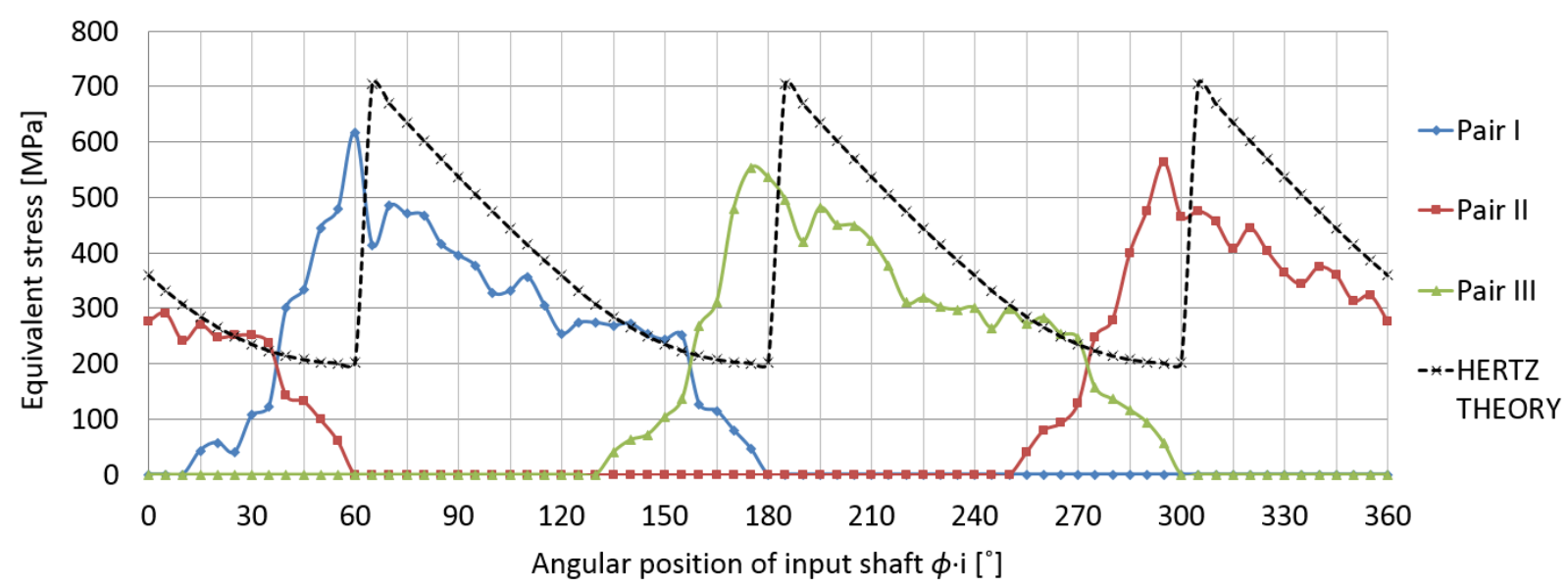

Figure 7: Comparison of contact stress values as a function of the angular position of the input shaft for the analytical and simulation models of three eccentric unit - cam wheel pairs.

Analysis of the contact stress distribution (Fig. 7) once again confirmed the convergence between the results of simulation tests and theoretical calculations. However, slight differences in obtained values were observed, especially for the angular positions of the input shaft, in which there is a change in the number of torque transmitting cam wheels. Moreover, the simulated contact stress distribution is shifted in phase relative to the theoretical results. This may be due to the fact that, in the analytical model, the solids are treated as immovable, while the FEM simulation model takes into account the displacements of the cooperating elements.

\section{IMPACT OF SELECTED PARAMETRES ON CONTACT STRESSES}

On the basis of the presented models, an analysis of the impact of selected transmission parameters on the maximum and average values of contact stress within the active surfaces of the cam wheels for the ERT with the gear ratio $i=10$ was performed. Fig. 8 shows the investigation results of the influence of the eccentricity value for the bearing 61804 (according to ISO 15) depending on the transmission load. Fig. 9 presents the results of the impact analysis of bearing dimensions for the ERT with the eccentricity value $e=2 \mathrm{~mm}$.
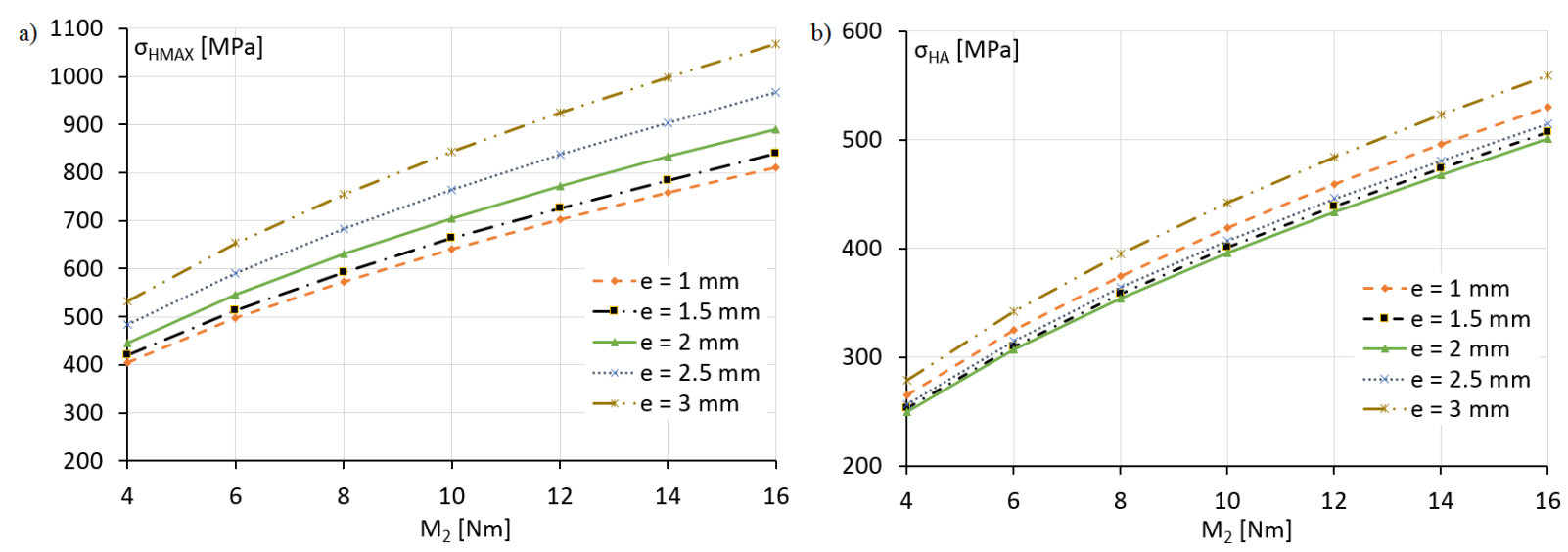

Figure 8: Impact of the eccentricity value on: a) maximum values of contact stress $\sigma_{\mathrm{HMAX}}$,

b) average values of contact stress $\sigma_{\mathrm{HA}}$.

The graphs in Fig. 8 indicate that the maximum and average values of contact stress in the ERT increase as the eccentricity increases. This is due to the fact that the value of Hertz stresses depends on the radius of curvature of the cam profile (13), the value of which varies 
along with the change in eccentricity values. In addition, it can be observed that the higher the eccentricity value, the more rapid the increase in the value of contact stress. It is worth noting that, for the eccentricity values in the range of $e=1-2 \mathrm{~mm}$, the change in the average values of contact stress is small.
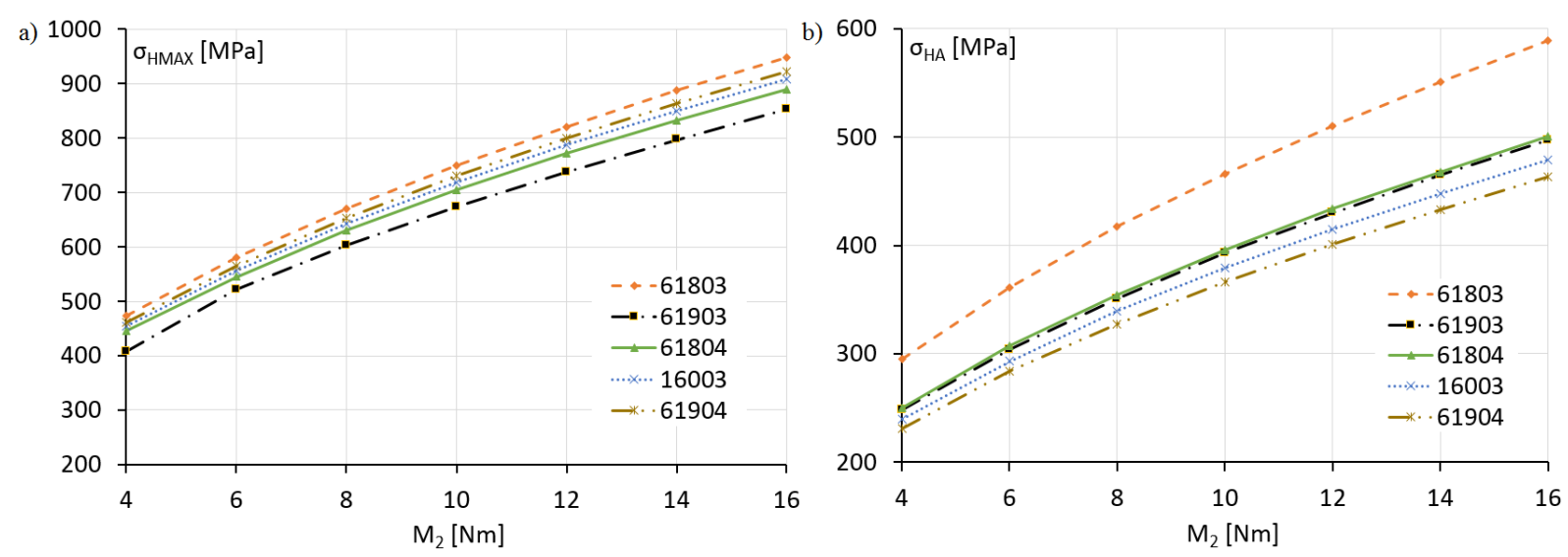

Figure 9: Impact of the bearing dimensions on: a) maximum values of contact stress $\sigma_{\mathrm{HMAX}}$,

b) average values of contact stress $\sigma_{\mathrm{HA}}$.

The analysis of the influence of bearing dimensions on the contact stresses in the ERT (Fig. 9) shows that the bearing width has a greater effect on contact stresses than its outside diameter. When comparing bearings of the same width (61903 and 61804), it can be concluded that the larger the diameter of the bearing, the higher the value of the maximum contact stress, however, the value of the average stress does not change significantly. The smallest maximum values of contact stress were obtained for the bearing 61903, while the smallest average values, for the bearing 61904. The least advantageous results in regard to the maximum and average contact stress were obtained for the bearing 61803 .

\section{CONCLUSION}

The theoretical analyses and simulations presented in the article allow the determination of the values of stress within the contact area of the eccentric units and the cam wheels in the eccentric rolling transmission. The results of 2D FEM simulation for one eccentric unit - cam wheel pair were in a good compatibility with theoretical values, however showed, that the maximal contact stresses (for adopted input parameters), which occurred near the vertex of the cam wheel, significantly exceeded the allowable stress numbers $\sigma_{\mathrm{Hlim}}$. The $3 \mathrm{D}$ simulation indicated that using at least three eccentric unit - cam wheel pairs allows the reduction of the maximum values of contact stresses to an acceptable level. By using the developed models, it is possible to execute comprehensive strength calculations as well as define load capacity of the new transmission of this type.

The impact analysis of transmission parameters on the values of contact stress showed that eccentric rolling transmission is more sensitive to the eccentricity than bearing dimensions. Moreover, it is advantageous to choose a bearing with the largest possible width and small outside diameter and use a bush with the lowest possible eccentricity value (1$2 \mathrm{~mm})$.

In further research, it is planned to perform experimental tests of ERT prototypes in order to determine their efficiency and verify their load capacity as well as to identify components that have the greatest impact on the strength and stiffness of the entire transmission unit. Testing of transmission prototypes with different gear ratio is crucial to verify all theoretical assumptions. To make this possible, it is necessary to prepare appropriate manufacturing 
technology of the transmission components that ensures required shape and dimensional accuracy. This problem is the subject of the current research.

\section{ACKNOWLEDGEMENT}

The current research is supported by The Ministry of Science and Higher Education (Poland), projects 02/22/DSMK/1487 and 02/22/SBAD/1501.

\section{REFERENCES}

[1] Pabiszczak, S.; Myszkowski, A.; Staniek, R. (2016). Eccentric Rolling Transmission Gear, Patent PL 233658, Poznan

[2] Pabiszczak, S.; Myszkowski, M.; Staniek, R.; Macyszyn, L. (2017). Kinematic analysis and design of eccentric rolling transmission, Proceedings of the 2017 ASME International Mechanical Engineering Congress and Exposition, Paper V014T07A013, 6 pages, doi:10.1115/IMECE2017-70524

[3] Pabiszczak, S.; Ptaszyński, W.; Staniek, R. (2019). The impact of manufacturing accuracy of selected components on contact stress in the eccentric rolling transmission, Hamrol, A.; Kujawińska, A.; Barraza, M. (Eds.), Advances in Manufacturing II: Manufacturing 2019: Lecture Notes in Mechanical Engineering, Springer, Cham, 176-187, doi:10.1007/978-3-03018789-7_16

[4] Murakami, Y. (2017). Theory of Elasticity and Stress Concentration, John Wiley \& Sons, Chichester

[5] Brezeanu, L. C. (2015). Contact stresses between two cylindrical bodies: cylinder and cylindrical cavity with parallel axes - Part I: Theory and FEA 3D modeling, Procedia Technology, Vol. 19, 169-176, doi:10.1016/j.protcy.2015.02.025

[6] Brezeanu, L. C. (2015). Contact stresses between two cylindrical bodies - cylinder and cylindrical cavity with parallel axes - Part II: 2D and 3D FEA comparative study, Procedia Technology, Vol. 19, 177-184, doi:10.1016/j.protcy.2015.02.026

[7] Golovin, A.; Lafitsky, A.; Simuskhin, A. (2009). Experimental and theoretical research of cams wearing of cams mechanism, Proceedings of EUCOMES 08, 343-350, doi:10.1007/978-1-4020$\underline{8915-2 \_42}$

[8] Ondrasek, J. (2017). The stress distribution in the contact region of a cam mechanism general kinematic pair, Mechanisms, Transmissions and Applications, IFToMM 2017: Mechanisms and Machine Science, Vol. 52, 99-108, doi:10.1007/978-3-319-60702-3_11

[9] Bartkowiak, T.; Berglund, J.; Brown, C. A. (2018). Establishing functional correlations between multiscale areal curvatures and coefficients of friction for machined surfaces, Surface Topography: Metrology and Properties, Vol. 6, No. 3, Paper 034002, 11 pages, doi:10.1088/ 2051-672X/aac073

[10] Bartkowiak, T.; Staniek, R. (2016). Application of multi-scale areal curvature analysis to contact problem insights and innovations in structural engineering, mechanics and computation, Proceedings of the $6^{\text {th }}$ International Conference on Structural Engineering, Mechanics and Computation, 1823-1829, doi:10.1201/9781315641645-301

[11] Patil, S. S.; Karuppanan, S.; Atanasovska, I. (2019). A short review on frictional contact stress distribution in involute gears, Tribology in Industry, Vol. 41, No. 2, 254-266, doi:10.24874/ ti.2019.41.02.11

[12] Jabbour, T.; Asmar, G. (2015). Tooth stress calculation of metal spur and helical gears, Mechanism and Machine Theory, Vol. 92, 375-390, doi:10.1016/j.mechmachtheory.2015.06.003

[13] Jammal, A.; Wang, H.; Rong, Y. (2015). Spur gears static and dynamic meshing simulation and tooth stress calculation, MATEC Web of Conferences, Vol. 26, Paper 03001, 5 pages, doi:10.1051/matecconf/20152603001

[14] Hwang, S.-C.; Lee, J.-H.; Lee, D.-H.; Han, S.-H.; Lee, K.-H. (2013). Contact stress analysis for a pair of mating gears, Mathematical and Computer Modelling, Vol. 57, No. 1-2, 40-49, doi: $10.1016 /$ j.mcm.2011.06.055 
[15] Zhan, J.; Fard, M.; Jazar, R. (2015). A quasi-static FEM for estimating gear load capacity, Measurement, Vol. 75, 40-49, doi:10.1016/j.measurement.2015.07.036

[16] Li, X. Y.; Wang, N. N.; Lv, Y. G.; Zeng, Q. L.; Hidenori, K. (2016). Tooth profile modification and simulation analysis of involute spur gear, International Journal of Simulation Modelling, Vol. 15, No. 4, 649-662, doi:10.2507/IJSIMM15(4)6.358

[17] Zeng, Q. L.; Wang, K.; Wan, L. R.; Zhang, X. (2017). Accurate modelling and transient meshing analysis of involute spur gear based on the principle of gear shaping, International Journal of Simulation Modelling, Vol. 16, No. 2, 322-333, doi:10.2507/IJSIMM16(2)CO7

[18] Wen, Q.; Du, Q.; Zhai, X. (2019). An analytical method for calculating the tooth surface contact stress of spur gears with tip relief, International Journal of Mechanical Science, Vol. 151, 170180, doi:10.1016/j.ijmecsci.2018.11.007

[19] Gonzalez-Perez, I.; Fuentes-Aznar, A. (2017). Implementation of a finite element model for stress analysis of gear drives based on multi-point constraints, Mechanism and Machine Theory, Vol. 117, 35-47, doi:10.1016/j.mechmachtheory.2017.07.005

[20] Cheng, L. Z.; Liu, D. K.; Wang, Y.; Chen, A. Q. (2019). Load distribution and contact of axle box bearings in electric multiple units, International Journal of Simulation Modelling, Vol. 18, No. 2, 290-301, doi:10.2507/IJSIMM18(2)475

[21] Okorn, I.; Nagode, M.; Klemenc, J. (2018). Analysis on damage to rolling bearings at small turning angles, Strojniski vestnik - Journal of Mechanical Engineering, Vol. 64, No. 4, 209-215, doi:10.5545/sv-jme.2017.5063

[22] Li, S. (2014). Design and strength analysis methods of the trochoidal gear reducers, Mechanism and Machine Theory, Vol. 81, 140-154, doi:10.1016/j.mechmachtheory.2014.07.001

[23] Lei, L.; Shi, X. C.; Guan, T. M. (2012). Finite element analysis for cycloid gear and pin teeth of FA cycloid drive based on ANSYS, Applied Mechanics and Materials, Vol. 215-216, 1197-1200, doi:10.4028/www.scientific.net/AMM.215-216.1197

[24] Durdevic, D.; Andelic, N.; Maneski, T.; Milosevic-Mitic, V.; Durdevic, A.; Konjatic, P. (2019). Numerical-experimental determination of stress and deformation state in connecting lugs with the effect of contact area size, Technical Gazette, Vol. 26, No. 2, 380-384, doi:10.17559/TV20180122105145

[25] Halama, R.; Sofer, M.; Rojicek, J.; Fojtik, F.; Kolarik, K. (2017). A method for predicting ratcheting and wear in rolling contact fatigue, taking technological residual stresses into consideration, Technical Gazette, Vol. 24, Supl. 1, 7-14, doi:10.17559/TV-20140224213525

[26] International standard ISO 6336-2. (2006). Calculation of Load Capacity of Spur and Helical Gears - Part 2: Calculation of Surface Durability (Pitting), 33 pages, International Organization for Standardization, Geneva

[27] International standard ISO 6336-5. (2006). Calculation of Load Capacity of Spur and Helical Gears - Part 5: Strength and Quality of Materials, 43 pages, International Organization for Standardization, Geneva 